\title{
Frequency and quality of first aid offered by older adolescents: A cluster randomised crossover trial of school- based first aid courses
}

\author{
Alyssia Rossetto ${ }^{\text {Corresp., } 1,2}{ }$, Amy J Morgan ${ }^{1}$, Laura M Hart ${ }^{1,3}$, Claire M Kelly ${ }^{2}$, Anthony F Jorm ${ }^{1,2}$ \\ ${ }^{1}$ Melbourne School of Population and Global Health, The University of Melbourne, Melbourne, Victoria, Australia \\ 2 Mental Health First Aid Australia, Melbourne, Victoria, Australia \\ ${ }^{3}$ School of Psychology and Public Health, La Trobe University, Melbourne, Victoria, Australia \\ Corresponding Author: Alyssia Rossetto \\ Email address: alyssia.rossetto@unimelb.edu.au
}

Background. Research indicates that school-based first aid programs appear to improve students' knowledge and skills. However, evidence for their effectiveness is limited by a lack of rigorously designed studies. This research used a cluster randomised crossover trial to assess the effects of two different types of first aid training on the frequency and appropriateness of older adolescents' first aid behaviours towards their peers 12 months after training. Methods. Schools eligible to participate were government funded and able to accommodate first aid training and survey time for two consecutive Year 10 student cohorts. Four Australian public schools were matched in two pairs and randomly assigned to receive either physical first aid (PFA) or teen mental health first aid (tMHFA) training for their Year 10 student cohort (mean age 16 years). In the second year, the new Year 10 cohort received the other intervention. Four cohorts were randomised to receive PFA and four were randomised to receive tMHFA. Online surveys were administered at baseline and 12 months after training, measuring whether students had encountered a peer needing PFA, whether they had provided PFA, what actions they performed and, if applicable, why they had been unable to help the person. Only research staff analysing the data could be blinded to measurement occasion, school identity and condition. Results. Four cohorts received PFA and four received tMHFA. The results indicated that there were no differences between groups regarding the frequency of appropriate first aid actions performed 12 months after training. The most common types of PFA provided to a peer were sending for help and wound care. Students most commonly mentioned someone else attending to their peer or lacking skills or experience as reasons for not performing PFA actions.

Conclusions. More research that examines first aid behaviours using rigorous, longitudinal study designs is needed to establish the effectiveness of school-based first aid training for older adolescents.

Peer] reviewing PDF | (2020:04:48206:1:0:NEW 21 Jul 2020) 


\section{Frequency and quality of first aid offered by older}

2 adolescents: a cluster randomised crossover trial of

3 school-based first aid courses

4

5 Alyssia Rossetto $^{1,2}$, Amy J. Morgan ${ }^{1}$, Laura M. Hart ${ }^{1,3}$, Claire M. Kelly ${ }^{2}$, Anthony F. Jorm ${ }^{1,2}$ 6

$7{ }^{1}$ Population Mental Health Group, Centre for Mental Health, Melbourne School of Population

8 and Global Health, Level 4, 207 Bouverie Street, The University of Melbourne, Carlton,

9 Victoria, Australia, 3010

${ }^{2}$ Mental Health First Aid Australia, Level 6, 369 Royal Parade Parkville, Victoria, Australia, 113052.

$12{ }^{3}$ School of Psychology and Public Health, La Trobe University, Bundoora, Victoria, Australia, 133086

15 Corresponding Author:

16 Alyssia Rossetto

17 Centre for Mental Health, Melbourne School of Population and Global Health

18207 Bouverie Street

19 The University of Melbourne

20 Carlton, Victoria, Australia, 3010

21 Email address: alyssia.rossetto@unimelb.edu.au 


\section{Abstract}

24 Background. Research indicates that school-based first aid programs appear to improve

25 students' knowledge and skills. However, evidence for their effectiveness is limited by a lack of

26 rigorously designed studies. This research used a cluster randomised crossover trial to assess the

27 effects of two different types of first aid training on the frequency and appropriateness of older

28 adolescents' first aid behaviours towards their peers 12 months after training.

29 Methods. Schools eligible to participate were government funded and able to accommodate first

30 aid training and survey time for two consecutive Year 10 student cohorts. Four Australian public

31 schools were matched in two pairs and randomly assigned to receive either physical first aid

32 (PFA) or teen mental health first aid (tMHFA) training for their Year 10 student cohort (mean

33 age 16 years). In the second year, the new Year 10 cohort received the other intervention. Four

34 cohorts were randomised to receive PFA and four were randomised to receive tMHFA. Online

35 surveys were administered at baseline and 12 months after training, measuring whether students

36 had encountered a peer needing PFA, whether they had provided PFA, what actions they

37 performed and, if applicable, why they had been unable to help the person. Only research staff

38 analysing the data could be blinded to measurement occasion, school identity and condition.

39 Results. Four cohorts received PFA and four received tMHFA. The results indicated that there

40 were no differences between groups regarding the frequency of appropriate first aid actions

41 performed 12 months after training. The most common types of PFA provided to a peer were

42 sending for help and wound care. Students most commonly mentioned someone else attending to

43 their peer or lacking skills or experience as reasons for not performing PFA actions. 
44 Conclusions. More research that examines first aid behaviours using rigorous, longitudinal study

45 designs is needed to establish the effectiveness of school-based first aid training for older 46 adolescents.

47 Trial registration. This research is registered with the Australian New Zealand Clinical Trials 48 Registry (ACTRN12614000061639). Registered 20/01/2014, 49 https:/www.anzctr.org.au/Trial/Registration/TrialReview.aspx?id=365334\&isReview=true 50 Funding. This research was funded by Australian Rotary Health and the National Health and 51 Medical Research Council.

\section{Introduction}

The ability to provide first aid is an important set of skills for anyone of any age to have.

55 The provision of appropriate first aid to an ill or injured person can save a life, mitigate the severe consequences of sudden illness or injury, address minor injuries in a timely and effective way, and create a caring and reassuring environment until emergency services arrive.

First aid skills may be particularly important for groups who are often exposed to illness and injury, such as children and adolescents (Wilks \& Pendergast 2017). Rates of hospital admissions for conditions such as anaphylaxis are rising, particularly in the 5-14 year age group

61 (Mullins et al. 2015). Accidents and injuries are a leading cause of hospitalisation, morbidity and 62 mortality among children and adolescents in Australia and worldwide (Australian Institute of 63 Health and Welfare 2018; Global Burden of Disease Pediatrics Collaboration 2016; Pointer 64 2014). In Australia, the most common mechanisms of injury for young people aged between 11 65 and 17 are falls, road transport and intentional self-harm (Mitchell et al. 2018; Pointer 2014). 66 Transport-related injuries, collisions and falls are also the most common causes of major 
67 paediatric trauma in 11 to 15 year olds in the state of Victoria, and these injuries primarily occur

68 in settings outside the home and school (e.g. on roads, streets and highways, in recreation areas,

69 and in athletics and sports areas; Beck et al. 2019). This suggests that illnesses and injuries in

70 young people are common and take place in areas where bystanders, such as peers, may be

71 present and able to offer first aid.

72 One way to increase the proportion of young people equipped with first aid skills is to

73 offer first aid training to students in schools. Schools have an influential role in promoting

74 adolescent health and wellbeing, and provide access to the majority of young people from

75 diverse socioeconomic backgrounds. Although first aid training for students is not currently

76 mandatory in Australia, schools appear to be supportive of first aid courses for students, and first

77 aid principles align well with Australian school curriculum goals of developing students'

78 knowledge, skills, self-efficacy and resilience across various life domains (Wilks \& Pendergast

79 2017).

80 Many studies have assessed the effectiveness of school-based first aid programs.

81 Systematic reviews indicate that first aid training appears to improve students' knowledge and

82 skills in areas such as injury prevention, cardiopulmonary resuscitation (CPR) and use of

83 automatic external defibrillators (Plant \& Taylor 2013; Reveruzzi et al. 2016). However, existing

84 evidence for the effectiveness of school-based first aid programs is limited by a lack of well-

85 designed studies. Common methodological issues include a lack of random allocation, absence

86 of comparison or control groups, small or biased samples, failure to measure students' first aid

87 knowledge or experiences prior to completing school-based first aid training, and a lack of

88 justification for the topics addressed in the training (Reveruzzi et al. 2016). These issues indicate

89 that more rigorous study designs are needed to examine the acquisition and retention of first aid 
90 skills in adolescent students undertaking school-based first aid training. Studies that assess

91 whether first aid skills are used, and used appropriately, outside of learning and skills testing

92 settings are also needed to understand whether and how adolescents apply first aid when faced

93 with a real-life emergency.

94

The current article reports on a subset of results from a randomised controlled trial which

95

96

97

\section{Study design} appropriate PFA.

compared a physical first aid (PFA) course with an equivalent length mental health first aid course (teen Mental Health First Aid; tMHFA) to assess the effects of each type of training on older adolescents' PFA behaviours 12 months after the training. This study aimed to establish whether the training programs produced differences in the frequency with which students offered and provided PFA to peers experiencing an illness or injury and the amount of first aid provided that was in line with current PFA guidelines. It was hypothesised that students receiving the PFA course would offer PFA more often, provide PFA more often, and provide more appropriate PFA than students receiving the tMHFA course. The study also aimed to ascertain which PFA actions were most commonly performed amongst this age group and why first aid might not have been provided in situations where a peer required PFA. Lastly, the study aimed to assess predictors of

\section{Materials \& Methods}

The description below outlines the sections of the trial design and study methodology relevant to the aims of this research. It conforms to the CONSORT 2010 statement and extension for cluster randomised trials (Campbell et al. 2012). Full details of the trial and methodology can be found in Hart et al (2018). 
114 2017. Each school comprised one cluster and provided two cohorts of Year 10 students during

115 the study. Each school received both interventions, with one student cohort completing one

116 intervention in the first year, and a second student cohort completing the other intervention in the

117 second year. Schools enrolled in the trial were pair matched based on their Index of Community

118 Socio-Educational Advantage (ICSEA) and the size of their Year 10 cohort. Pairs were then

119 randomly assigned to receive either tMHFA or PFA for their Year 10 students in the first year of

120 the trial. In the second year, the new Year 10 students received the other intervention. This trial

121 design reduced the number of clusters required to achieve adequate participant numbers, enabled

122 counterbalancing across schools, and allowed analyses to control for within-school variance.

123 Participants and procedure

124 Schools in the Melbourne region which had expressed an interest in receiving mental

125 health first aid training for staff and students were contacted to discuss the research. Schools

126 eligible to participate were government funded and able to accommodate three 30-minute survey

127 sessions and three 75-minute training sessions during regular class time for two consecutive Year

12810 student cohorts. Upon completion of a research agreement signed by the school principal, the

129 research team enrolled and matched schools in the trial. The intervention sequence for each pair

130 of schools (i.e. whether schools received tMHFA or PFA first) was determined by the trial

131 manager using a random sequence generator. The trial's research assistant allocated the first

132 sequence to the first school enrolled in the trial (and its pair), and allocated the second sequence

133 to the second school (and its pair). Researchers, instructors, schools and students could not be

134 blinded to intervention type. Survey and training sessions were then scheduled, using 
135 information provided by schools regarding the number of Year 10 students and classes in their 136 cohorts.

137 All students in each cohort were eligible to complete evaluation surveys if they had

138 parental consent and provided assent by selecting a checkbox that confirmed they wished to

139 proceed at the beginning of each survey. Students, parents and teachers were informed about the

140 research through information sessions, electronic and hard copy information forms, and school-

141 based communications (e.g. newsletters). Opt-out (passive) parental consent was used; parents

142 could opt their child out of the training and/or surveys at any time by returning a signed form to 143 the school.

144 All surveys were hosted on the online platform Survey Monkey. Schools were emailed a

145 link to each survey, which was distributed to students through an intranet or student email

146 address. Students entered a unique participant identification number at the beginning of each

147 survey, which enabled their responses to be matched over time but did not permit them to be

148 identified by the researchers. Students completed a baseline survey one week prior to the first

149 training session, a post-course survey up to one week after the final training session, and a

150 follow-up survey 12 months after the final training session.

151

All students were eligible to take part in the training allocated to their cohort if they had

152 parental consent. The PFA and tMHFA training programs each consisted of three 75 -minute

153 classroom-based sessions, with sessions typically beginning one week after completion of the

154 baseline survey and delivered one week apart. Each program was presented by trained external

155 instructors. Table 1 summarises the content of each program by session. The content covered

156 appropriate responses to health problems that adolescents were likely to encounter in their peers.

157 PFA content was delivered by accredited St John Ambulance and Red Cross instructors through 
158 didactic instruction, group discussion, demonstrations and practical activities with mannequins,

159 bandages and splints. The course was developed for this research and was shorter in duration and

160 more limited in content than accredited first aid courses offered in Australia. tMHFA is a skills-

161 based program that teaches adolescents how to recognise and respond to a peer experiencing

162 mental ill health. Courses were delivered by accredited tMHFA instructors through a Powerpoint

163 presentation, films, role-play activities, group discussion, small group activities, a manual and

164 workbook activities (Hart et al. 2016). Students in both interventions received a certificate of

165 completion at the end of their training.

166 [Insert Table 1 about here]

167 This research was registered with the Australian New Zealand Clinical Trials Registry

168 (ACTRN12614000061639, available from

169 https://www.anzctr.org.au/Trial/Registration/TrialReview.aspx?id=365334\&isReview=true).

170 Ethics approval was obtained from the University of Melbourne's Human Research Ethics

171 Committee (HREC1341238) and the state government education department for Victoria

172 (2014_002268).

\section{Measures}

174 The questions described below were administered during the baseline and 12-month

175 follow-up surveys. Post-course surveys did not include these questions as it was unlikely that

176 students would have had an opportunity to administer first aid in the time between completing

177 the training and beginning the post-course survey. As there are no standardised scales in this area

178 of research, questions from the First Aid Experiences Questionnaire (Hart et al. 2019; Hart et al.

179 2016; Jorm et al. 2005) were adapted to ask respondents about physical first aid situations they

180 had encountered. 

experiencing mental health problems (data reported elsewhere; see Hart et al. 2016; Hart et al. 2018). The next section asked 'In the last 12 months (baseline)/Since completing the first aid course 12 months ago (follow-up), have you come across someone about your age (i.e. between responded 'No' or 'I don't want to answer this question' moved on to the next section of the survey, while students who answered 'Yes' or 'Not sure' proceeded to answer additional questions about their experiences.

Students were asked to type in the number of people about their age they had encountered

were asked to describe what they did to help the person (free text response).

196 follow-up.

\section{Sample size calculation}

Sample size calculations conservatively estimated 100 Year 10 students per school, with students per intervention ( $n=800$ students in total). The estimated intraclass correlation for students at the school cluster level was 0.003 , based on findings from previous research (Hart et 
204 limited. The study assumed a 0.70 correlation between pre- and post-intervention measurements, 205 resulting in 0.80 power to detect small $(d=0.17)$ group-by-measurement occasion differences at $206 \alpha=0.05$.

\section{Statistical analysis}

Primary research outcomes were analysed at the individual level. Although this trial used

209

210

211

212

213

214

215

216

217

218

219

220

221

222

223

224

225

cluster randomisation, this research aimed to assess the effect of each type of first aid training on students' subsequent behaviour towards their peers, rather than the effects of the training on the whole school community. Research staff analysing the data were blinded to measurement occasion, school identity and condition.

Free text responses describing first aid provided to a peer were analysed using a coding framework developed for this study, which was based on current PFA guidelines (https://resus.org.au/guidelines/) and content analysis approaches (Crowe et al. 2015). Each code corresponded to a topic discussed in the PFA sessions (e.g. check airway, asthma, wound care) and included instructions, examples and counter-examples to guide coder fidelity. Three members of the research team developed the initial coding frame, which was refined through discussion and double-coding of sample responses (selected to represent different codes). Coding discrepancies were discussed until consensus was reached. After finalising the coding framework, the remaining responses were coded. Responses were assigned a value of 1 if they corresponded to a first aid action covered in the training. Responses which were incorrect, inappropriate, or did not relate to any other codes in the coding frame were coded as 0 .

Responses could be coded into more than one category. Researchers coding and analysing data were blinded to measurement occasion, school identity and intervention. Interrater reliability 
226 between coders was kappa $=0.88, \mathrm{p}<0.001$. This coding frame is available as a supplemental 227 file.

228

229

230

231

232

233

234

235

236

237

238

239

240

241

242

243

244

245

246

247

248

Free text responses describing reasons for not providing first aid were analysed using a second coding framework, which was developed through content analysis of the open-ended responses to this question (Crowe et al. 2015). Two members of the research team developed the initial coding frame which was refined through discussion. One researcher then coded all responses. Responses which could not be interpreted, did not make sense or required the coder to make strong assumptions about the student's meaning were categorised as 'unable to code' and excluded from subsequent analyses. This coding frame is available as a supplemental file.

Data were analysed using percent frequencies, chi-square analyses (using Cramer's V as a measure of effect size) and logistic regression. The intraclass correlation between appropriate first aid given and school cohort was 0.03, suggesting that school-level clustering had little influence on the data. Analyses were conducted using SPSS 25.

\section{Results}

[Insert Table 2 about here]

Table 2 shows the number of students allocated to each intervention, participant numbers at each time point and data on the number of students who encountered a person needing physical first aid, offered first aid, and provided appropriate first aid. The mean age of students completing the baseline survey was 15.87 years $(\mathrm{SD}=0.52) ; 44.7 \%$ were female and $72.5 \%$ spoke English as a first language (see Hart et al. 2018 for full details). Of the students responding to the section on experiences of first aid, the mean age was 15.87 years $(\mathrm{SD}=0.51), 46.4 \%$ were female and $76.6 \%$ spoke English as a first language. Chi-square analyses indicated that at both 
249 baseline and follow-up, there were no significant differences between interventions regarding the

250 number of students who had encountered a person needing physical first aid in the last 12

251 months, or in the proportion of students who offered help to the person they knew best.

252 However, at both time points, the group receiving PFA training provided significantly more

253 appropriate first aid than the group receiving tMHFA. Logistic regressions that assessed

254 intervention $\mathrm{x}$ time interactions for appropriate provision of PFA (controlling for age, gender,

255 English as first language, school, intervention received, number of first aid sessions attended and

256 whether appropriate PFA was provided at baseline) confirmed that appropriate PFA provided at

257 baseline was the only significant predictor of appropriate help at each time point. Receipt of PFA

258 training did not appear to improve the frequency or quality of students' first aid actions.

259 Of the total number of open-ended responses describing first aid provided to a peer,

$26060.3 \%$ were categorised as inadequate or ineffective. These responses included: talking to,

261 calming or comforting the person with no mention of other actions taken; taking a peer to the

262 school nurse or sick bay; offering assistance after the emergency had passed (e.g. "Offered to

263 carry person's books whilst their leg was in a moon boot"); and responses that did not describe a

264 specific first aid action (e.g. "Asked if there was anything I could do for them", "Assist them in

265 any way possible to make sure they were okay"). Table 3 summarises the most common types of

266 appropriate physical first aid provided to a peer across both time points.

267 [Insert Table 3 about here]

268 Table 4 summarises reasons given for not providing first aid at both time points. The

269 most common reasons were because someone else was already providing first aid, because the

270 student perceived their skill set or experience to be inadequate and because practical constraints

271 precluded the provision of first aid. 
272 [Insert Table 4 about here]

273

\section{Discussion}

275

The results of this study indicate that brief PFA training does not appear to affect the

276 frequency of appropriate first aid actions performed by older adolescents 12 months later.

277 Despite significant differences between the PFA and tMHFA groups at follow-up, pre-existing

278 differences at baseline suggested that the program was not effective at changing behaviour. A

279 lack of improvement in, or retention of, adolescents' first aid skills at 12 month follow-up is an

280 atypical finding in the literature on school-based first aid programs (e.g. Moore et al. 1992). One

281 explanation for this finding may be that the bespoke, shortened PFA course used in this research

282 may have reduced effectiveness when compared with lengthier, accredited PFA programs,

283 although at just under four hours' duration it is somewhat longer than other first aid courses

284 assessed in school settings (Reveruzzi et al. 2016). This finding may also have resulted from the

285 methodology used to assess first aid responses. Other studies of school-based first aid programs

286 use knowledge or skills assessments to evaluate students' first aid competencies, while this

287 research used an open-ended, free text response question. Many responses were brief or lacked

288 key details which would have enabled coders to assess the adequacy of students' first aid actions

289 and assign a valid code. The resultant loss of data likely contributed to the null effects found in

290 the analyses.

291

Analysis of the types of appropriate first aid provided to peers indicated that first aid was

292 provided for injuries such as wounds, sprains/strains and fractures/dislocations. This highlights

293 the importance of designing first aid courses for young people that enables them to address

294 injuries and illnesses common to adolescence (Reveruzzi et al. 2016). Adolescents who were

295 unable to help a peer who needed first aid cited a range of reasons for this, including that others

Peer) reviewing PDF | (2020:04:48206:1:0:NEW 21 Jul 2020) 
296 were already providing first aid (reported more often by PFA participants) and a belief that their

297 skills and experience were not adequate (reported more often by tMHFA participants). It appears

298 that only the reason related to lack of skill or experience has been reported previously in this age

299 group (Kanstad et al. 2011; Ma et al. 2015; Omi et al. 2008). These results should be regarded as

300 preliminary as it is uncommon for studies to examine reasons for not providing first aid in

301 response to a real-life emergency. Future research should attempt to replicate these findings with

302 different, larger samples of adolescents and endeavour to understand these reasons in greater

303 depth. Semi-structured interviews may offer insight into why adolescents with first aid training

304 believe they lack the skills to provide first aid, or why they may feel reluctant to provide first aid

305 to a peer (c.f. Wilks et al. 2016, who found that primary school-aged children were less likely to

306 feel confident helping a friend or same-aged stranger than a family member). This information

307 could be used by course developers to address perceived barriers to helping among adolescents

308 during training, and assess whether this affects rates of first aid provision.

309

Although further research is needed to better understand how first aid skills can best be

310 acquired, retained and used outside of learning and testing environments, the results of this study

311 suggest that schools can maximise the utility and relevance of school-based first aid programs in

312 two main ways. Firstly, schools can endeavour to ensure that their first aid programs contain topics

313 that are appropriate and useful for the target age group. The results of this research imply that the

314 most commonly used first aid skills were performed in response to injuries and illnesses common

315 to adolescence. Courses which incorporate content that reflects students' developmental stage

316 alongside basic life support steps may increase the likelihood of young people applying first aid to

317 a peer in an emergency, which may ultimately contribute to reductions in injury-related morbidity

318 and mortality (Tannvik et al. 2012). A second, complementary suggestion for schools is to consider 
319 introducing a first aid educational pathway into the curriculum that enables students to learn age320 appropriate first aid skills during each school year (De Buck et al. 2015; Wilks \& Pendergast 321 2017). A first aid educational pathway, such as the one developed by De Buck and colleagues (De

322 Buck et al. 2015) may serve many purposes, including revision of knowledge and skills from 323 previous years alongside acquisition of new skills, improving students' confidence and 324 competence in applying first aid, and improving teachers' confidence in teaching first aid to 325 students of any age. The pathway could also be developed in consultation with students to ensure 326 that it addresses topics and concerns that are important to them, such as particular barriers to 327 providing first aid (see Table 4). Embedding regular first aid lessons into the school curriculum, 328 and including student input in their development, can help to normalise the subject and increase students' comfort, self-efficacy, knowledge and skills in this area (Wilks \& Pendergast 2017). This research responds to calls in the first aid literature for more randomised controlled trials (Van de Velde et al. 2009), particularly ones assessing school-based first aid training and 332 first aid behaviours (Reveruzzi et al. 2016). The study used a rigorous cluster-randomised crossover trial methodology with longitudinal follow-up, and recruited a large, diverse sample of schools and adolescents. The structure and timing of each first aid intervention was matched to improve the likelihood that any changes to behaviour would be due to program content and not an artefact of undertaking an activity outside of the usual curriculum. The content was designed to cover key first aid skills, such as CPR, and first aid injuries and emergencies common to adolescence, such as strains, sprains, wounds and anaphylaxis, to increase its relevance to, and utility for, the target audience (De Buck et al. 2015; Reveruzzi et al. 2016). The findings also

340 have ecological validity, as they provide some insight into whether and how first aid skills were

341 used outside of learning and testing environments, and why they were not used. 
343 baseline and 12 month follow-up means that the research could not examine whether knowledge

344 or motivation to assist were retained up to a point (e.g. three or six months after training;

345 Andresen et al. 2008) before dropping off. As the questionnaire did not ask about prior first aid

346 training at baseline, or whether students had undertaken additional first aid training between

347 baseline and follow-up, the analyses could not control for these variables, or clarify whether any

348 changes were due to the first aid training delivered as part of this research. The questionnaire

349 also did not ask students what the problem requiring first aid was, and so it is not known whether

350 the first aid provided was appropriate for the situation, or administered effectively; students'

351 ability to correctly perform the first aid actions they were taught was not assessed. The small

352 number of students responding to the follow-up survey, and the brief explanations of their first

353 aid actions, precluded a more thorough assessment of first aid behaviour and reasons for not

354 helping at 12-month follow-up. As the research relied on self-report and students' recollection of

355 events that may have happened several months earlier, recall bias may have affected the quantity,

356 quality and validity of the data. Lastly, a large proportion of open-ended responses could not be

357 coded, which considerably reduced both the quantity and quality of data. Several of these

358 limitations are being addressed in another large-scale trial comparing tMHFA and PFA which is

359 currently underway, e.g. offering remuneration to increase participation rates, asking what the

360 problem requiring first aid was and including questions about intentions and confidence to

361 provide first aid to a peer experiencing different illnesses and injuries. It is anticipated that these

362 changes will enhance the amount and quality of data on first aid actions performed by

363 adolescents.

364

365 Conclusions 
The findings of this research highlight the need for more rigorously designed longitudinal

367

368

369

370

371

372

373

374

375

376

377

378

379

380

381

382

383

384

385

386

387

388

389

390

391

392

393

394

395

396

397

398

399

400

401

402

studies to establish the effectiveness of school-based first aid programs, and more research that

focuses on first aid behaviour in response to emergencies that adolescents may encounter. An

improved understanding of first aid skill retention and use will contribute to the development of

engaging and relevant health education for young people.

\section{Acknowledgements}

The authors wish to thank Don Dumayas for developing the coding frame used to analyse the

open-ended responses, Catherine Johnson and Penny Cropper for coding the responses and Betty

Kitchener who assisted with the grant application which funded this research.

\section{References}

Andresen D, Arntz HR, Grafling W, Hoffmann S, Hofmann D, Kraemer R, Krause-Dietering B, Osche S, Wegscheider K. 2008. Public access resuscitation program including defibrillator training for laypersons: A randomized trial to evaluate the impact of training course duration. Resuscitation 76:419-424. 10.1016/j.resuscitation.2007.08.019

Australian Institute of Health and Welfare. 2018. Deaths in Australia. Canberra, ACT, Australia: Australian Institute of Health and Welfare.

Beck B, Teague W, Cameron P, Gabbe BJ. 2019. Causes and characteristics of injury in paediatric major trauma and trends over time. Archives of Disease in Childhood 104:256-261. 10.1136/archdischild-2018-315565

Campbell MK, Piaggio G, Elbourne DR, Altman DG. 2012. Consort 2010 statement: extension to cluster randomised trials. British Medical Journal 345. 10.1136/bmj.e5661

Crowe M, Inder M, Porter R. 2015. Conducting qualitative research in mental health: Thematic and content analyses. Australian \& New Zealand Journal of Psychiatry 49:616-623. 10.1177/0004867415582053

De Buck E, Van Remoortel H, Dieltjens T, Verstraeten $\mathrm{H}$, Clarysse M, Moens O, Vandekerckhove P. 2015. Evidence-based educational pathway for the integration of first aid training in school curricula. Resuscitation 94:8-22. 10.1016/j.resuscitation.2015.06.008

Global Burden of Disease Pediatrics Collaboration. 2016. Global and national burden of diseases and injuries among children and adolescents between 1990 and 2013: Findings from the global burden of disease 2013 study. JAMA Pediatrics 170:267-287. 10.1001/jamapediatrics.2015.4276

Hart LM, Bond KS, Morgan AJ, Rossetto A, Cottrill FA, Kelly CM, Jorm AF. 2019. Teen Mental Health First Aid for years 7-9: a description of the program and an initial evaluation. International Journal of Mental Health Systems 13:71. 10.1186/s13033-019-0325-4

PeerJ reviewing PDF | (2020:04:48206:1:0:NEW 21 Jul 2020) 
403

404

405

406

407

408

409

410

411

412

413

414

415

416

417

418

419

420

421

422

423

424

425

426

427

428

429

430

431

432

433

434

435

436

437

438

439

440

441

442

443

444

445

446

447

448

449

450

Hart LM, Mason RJ, Kelly CM, Cvetkovski S, Jorm AF. 2016. 'teen Mental Health First Aid': a description of the program and an initial evaluation. International Journal of Mental Health Systems 10. 10.1186/s13033-016-0034-1

Hart LM, Morgan AJ, Rossetto A, Kelly CM, Mackinnon A, Jorm AF. 2018. Helping adolescents to better support their peers with a mental health problem: A cluster-randomised crossover trial of teen Mental Health First Aid. Australian \& New Zealand Journal of Psychiatry 52:638 - 651. 10.1177/0004867417753552

Jorm AF, Kitchener BA, Mugford SK. 2005. Experiences in applying skills learned in a mental health first aid training course: A qualitative study of participants' stories. BMC Psychiatry 5:43. 10.1186/1471-244X-5-43

Kanstad BK, Nilsen SA, Fredriksen K. 2011. CPR knowledge and attitude to performing bystander CPR among secondary school students in Norway. Resuscitation 82:10531059. 10.1016/j.resuscitation.2011.03.033

Ma A, Wong K, Tou A, Vyas L, Wilks J. 2015. CPR knowledge and attitudes among high school students aged 15-16 in Hong Kong. Hong Kong Journal of Emergency Medicine 22:3-13. 10.1177/102490791502200101

Mitchell RJ, Curtis K, Foster K. 2018. A 10-year review of child injury hospitalisations, health outcomes and treatment costs in Australia. Injury Prevention 24:344. 10.1136/injuryprev2017-042451

Moore PJ, Plotnikoff RC, Preston GD. 1992. A study of school students' long term retention of expired air resuscitation knowledge and skills. Resuscitation 24:17-25. 10.1016/03009572(92)90170-H

Mullins RJ, Dear KBG, Tang MLK. 2015. Time trends in Australian hospital anaphylaxis admissions in 1998-1999 to 2011-2012. Journal of Allergy and Clinical Immunology 136:367-375. 10.1016/j.jaci.2015.05.009

Omi W, Taniguchi T, Kaburaki T, Okajima M, Takamura M, Noda T, Ohta K, Itoh H, Goto Y, Kaneko S, Inaba H. 2008. The attitudes of Japanese high school students toward cardiopulmonary resuscitation. Resuscitation 78:340-345. 10.1016/j.resuscitation.2008.03.233

Plant N, Taylor K. 2013. How best to teach CPR to schoolchildren: A systematic review. Resuscitation 84:415-421. 10.1016/j.resuscitation.2012.12.008

Pointer S. 2014. Hospitalised injury in children and young people 2011-12. In: Australian institute of Health and Welfare, editor. Injury research and statistics series no. 91, Catalogue no. INJCAT 167 ed. Canberra, ACT, Australia: Australian Institute of Health and Welfare.

Reveruzzi B, Buckley L, Sheehan M. 2016. School-based first aid training programs: A systematic review. Journal of School Health 86:266-272. 10.1111/josh.12373

Tannvik TD, Bakke HK, Wisborg T. 2012. A systematic literature review on first aid provided by laypeople to trauma victims. Acta Anaesthesiologica Scandinavica 56:1222-1227. 10.1111/j.1399-6576.2012.02739.x

Van de Velde S, Heselmans A, Roex A, Vandekerckhove P, Ramaekers D, Aertgeerts B. 2009. Effectiveness of nonresuscitative first aid training in laypersons: A systematic review. Annals of Emergency Medicine 54:447-457.e445. 10.1016/j.annemergmed.2008.11.005

Wilks J, Kanasa H, Pendergast D, Clark K. 2016. Emergency response readiness for primary school children. Australian Health Review 40:357-363. 10.1071/AH15072

Wilks J, Pendergast D. 2017. Skills for life: First aid and cardiopulmonary resuscitation in schools. Health Education Journal 76:1009-1023. 10.1177/0017896917728096

Peer) reviewing PDF | (2020:04:48206:1:0:NEW 21 Jul 2020) 


\section{Table 1 (on next page)}

Structure and content of first aid interventions 
1 Table 1. Structure and content of first aid interventions.

\begin{tabular}{|c|c|c|}
\hline $\begin{array}{c}\text { Session } \\
\text { number and } \\
\text { duration }\end{array}$ & PFA & tMHFA \\
\hline $\begin{array}{l}\text { Session } 1 \\
\text { ( } 75 \text { minutes) }\end{array}$ & $\begin{array}{l}\text { First aid and the DRSABCD } \\
\text { action plan } \\
\text { - Where to start } \\
\text { - When and how to call emergency } \\
\text { services } \\
\text { - How to manage a conscious person } \\
\text { - How to manage an unconscious } \\
\text { person } \\
\text { - When and how to perform } \\
\text { cardiopulmonary resuscitation } \\
\text { - When and how to use an automated } \\
\text { external defibrillator }\end{array}$ & $\begin{array}{l}\text { Mental health and mental health } \\
\text { problems } \\
\text { - What is mental health? } \\
\text { - What are mental health problems? } \\
\text { - Types of mental health problems } \\
\text { - Impact on young people } \\
\text { - What is stigma? } \\
\text { - Types of appropriate help }\end{array}$ \\
\hline $\begin{array}{l}\text { Session } 2 \\
\text { (75 minutes) }\end{array}$ & $\begin{array}{l}\text { Basic first aid for: } \\
\text { - Sprains } \\
\text { - Strains } \\
\text { - Wound care } \\
\text { - Fractures and dislocations } \\
\text { - Concussion } \\
\text { - Asthma }\end{array}$ & $\begin{array}{l}\text { Helping a friend in a mental health } \\
\text { crisis } \\
\text { - What is mental health first aid? } \\
\text { - What is a mental health crisis? } \\
\text { - Using the tMHFA action plan to help } \\
\text { a friend in crisis } \\
\text { - Recovery position }\end{array}$ \\
\hline $\begin{array}{l}\text { Session } 3 \\
\text { (75 minutes) }\end{array}$ & $\begin{array}{l}\text { Basic first aid for: } \\
\text { - Anaphylaxis } \\
\text { - Poisons } \\
\text { - Exposure to heat } \\
\text { - Exposure to cold } \\
\text { - Diabetes } \\
\text { - Seizure }\end{array}$ & $\begin{array}{l}\text { Helping a friend who is developing a } \\
\text { mental health problem } \\
\text { - The importance of acting early } \\
\text { - Using the tMHFA action plan to help } \\
\text { a friend in crisis } \\
\text { - Helpful links and resources }\end{array}$ \\
\hline Action plan & $\begin{array}{l}\text { D: Danger } \\
\text { R: Response } \\
\text { S: Send for help } \\
\text { A: Open airway } \\
\text { B: Check for breathing } \\
\text { C: Start CPR } \\
\text { D: Attach defibrillator }\end{array}$ & $\begin{array}{l}\text { Look: Look for warning signs } \\
\text { Ask: Ask how they are } \\
\text { Listen: Listen up } \\
\text { Help: Help them connect with an adult } \\
\text { Your Friend: Your friendship is } \\
\text { important }\end{array}$ \\
\hline
\end{tabular}

2 Note. PFA: Physical First Aid; tMHFA: teen Mental Health First Aid 


\section{Table 2 (on next page)}

Participant numbers and analyses of first aid offered and provided by intervention 
1 Table 2. Participant numbers and analyses of first aid offered and provided by intervention.

\begin{tabular}{|c|c|c|c|c|}
\hline Description & tMHFA & PFA & Total & Significance \\
\hline Sample size at intervention allocation & 989 & 953 & 1942 & \\
\hline \multicolumn{5}{|l|}{ Baseline data } \\
\hline Number of surveys submitted & 821 & 803 & 1624 & \\
\hline Participation rate & $83 \%$ & $84 \%$ & $83.5 \%$ & \\
\hline $\begin{array}{l}\text { Number of students responding 'Yes' or 'Not sure' to the } \\
\text { question 'In the last } 12 \text { months have you come across } \\
\text { someone about your age who has required first aid because } \\
\text { of an emergency or injury?' }\end{array}$ & 404 & 394 & 798 & $\begin{array}{c}X^{2}(1)=0.039 \\
\mathrm{p}=0.844, \mathrm{~V}=0.01\end{array}$ \\
\hline $\begin{array}{l}\text { Number of students responding 'Yes' or 'Not sure' to the } \\
\text { question 'Did you offer help to the person you knew best?' }\end{array}$ & $346(85.6 \%)$ & $339(86.0 \%)$ & $685(85.8 \%)$ & $\begin{array}{c}X^{2}(1)=0.020 \\
\mathrm{p}=0.887, \mathrm{~V}=0.01\end{array}$ \\
\hline $\begin{array}{l}\text { Number of students providing appropriate physical first aid } \\
\text { to a peer }\end{array}$ & $\begin{array}{c}38 / 260 \text { responses } \\
(14.6 \%)\end{array}$ & $\begin{array}{l}80 / 272 \text { responses } \\
(29.4 \%)\end{array}$ & $\begin{array}{c}118 / 532 \text { responses } \\
(22.2 \%)\end{array}$ & $\begin{array}{c}X^{2}(1)=16.861 \\
\mathrm{p}=0.000, \mathrm{~V}=0.18\end{array}$ \\
\hline \multicolumn{5}{|l|}{ 12-month follow-up data } \\
\hline Number of surveys submitted & 465 & 429 & 894 & \\
\hline Participation rate (as \% of baseline surveys submitted) & $56.6 \%$ & $53.4 \%$ & $55.0 \%$ & \\
\hline $\begin{array}{l}\text { Number of students responding 'Yes' or 'Not sure' to the } \\
\text { question 'In the last } 12 \text { months have you come across } \\
\text { someone about your age who has required first aid because } \\
\text { of an emergency or injury?' }\end{array}$ & 154 & 129 & 283 & $\begin{array}{c}X^{2}(1)=1.373 \\
\mathrm{p}=0.241, \mathrm{~V}=0.04\end{array}$ \\
\hline $\begin{array}{l}\text { Number of students responding 'Yes' or 'Not sure' to the } \\
\text { question 'Did you offer help to the person you knew best?' }\end{array}$ & $133(86.4 \%)$ & $109(84.5 \%)$ & $242(85.5 \%)$ & $\begin{array}{c}X^{2}(1)=0.282 \\
\mathrm{p}=0.595, \mathrm{~V}=0.03\end{array}$ \\
\hline $\begin{array}{l}\text { Number of students providing appropriate physical first aid } \\
\text { to a peer }\end{array}$ & $\begin{array}{l}16 / 96 \text { responses } \\
\quad(16.7 \%)\end{array}$ & $\begin{array}{l}27 / 85 \text { responses } \\
\quad(31.8 \%)\end{array}$ & $\begin{array}{c}43 / 181 \text { responses } \\
(23.8 \%)\end{array}$ & $\begin{array}{c}X^{2}(1)=5.674 \\
\mathrm{p}=0.017, \mathrm{~V}=0.18\end{array}$ \\
\hline
\end{tabular}




\section{Table 3(on next page)}

Most common types of first aid provided to a peer with a physical injury or illness 
Table 3. Most common types of first aid provided to a peer with a physical injury or illness.

\begin{tabular}{|c|c|c|c|c|c|}
\hline $\begin{array}{l}\text { First aid response } \\
\text { (n) }\end{array}$ & Example quote & $\begin{array}{l}\text { Percentage of all } \\
\text { responses }(n=916)\end{array}$ & $\begin{array}{c}\text { Percentage of } \\
\text { appropriate } \\
\text { responses }(n=172)\end{array}$ & $\begin{array}{c}\text { n }(\%) \text { of } \\
\text { appropriate } \\
\text { responses from } \\
\text { PFA group }\end{array}$ & $\begin{array}{c}\mathbf{n}(\%) \text { of } \\
\text { appropriate } \\
\text { responses from } \\
\text { tMHFA group }\end{array}$ \\
\hline Send for help (52) & $\begin{array}{l}\text { "I asked if they required } \\
\text { any medical attention and } \\
\text { rang } 000 "(\mathrm{P} 1612, \\
\text { baseline) }\end{array}$ & 5.7 & 30.4 & $33(63.5)$ & $19(36.5)$ \\
\hline Wound care (48) & $\begin{array}{l}\text { "Well it was my nephew } \\
\text { and he had a deep cut on } \\
\text { his head, I first got a } \\
\text { towel and put water on it } \\
\text { and told him to hold it } \\
\text { against the wound, and as } \\
\text { it was still bleeding and } \\
\text { no one was home - I } \\
\text { dialled } 000 \text { to ask for } \\
\text { help and it went on from } \\
\text { there." (P74, follow-up) }\end{array}$ & 5.2 & 28.1 & $34(70.8)$ & $14(29.2)$ \\
\hline $\begin{array}{l}\text { Strains and sprains } \\
(26)\end{array}$ & $\begin{array}{l}\text { "Performed RICER" } \\
\text { (P992, follow-up) }\end{array}$ & 2.8 & 15.2 & $13(50.0)$ & $13(50.0)$ \\
\hline $\begin{array}{l}\text { Fractures and } \\
\text { dislocations (13) }\end{array}$ & $\begin{array}{l}\text { "Made a sling out of my } \\
\text { T-shirt and carried him to } \\
\text { a safe place" (P976, } \\
\text { baseline) }\end{array}$ & 1.4 & 7.6 & $11(84.6)$ & $2(15.4)$ \\
\hline
\end{tabular}


7 first aid sessions attended) were non-significant, with the exception of sending for help. The only significant predictor of sending for help at 12 -

8 month follow-up was sending for help at baseline $(\mathrm{p}=0.001)$. 


\section{Table 4 (on next page)}

Most common reasons for not providing first aid to a peer with a physical injury or illness 
1 Table 4. Most common reasons for not providing first aid to a peer with a physical injury or illness.

\begin{tabular}{|c|c|c|c|c|c|}
\hline Reason (n) & Example & $\begin{array}{l}\text { Percentage of all } \\
\text { responses }(n=158)\end{array}$ & $\begin{array}{c}\begin{array}{c}\text { Percentage of } \\
\text { codable responses } \\
(n=109)\end{array} \\
\end{array}$ & $\begin{array}{c}\text { n (\%) of codable } \\
\text { responses from PFA } \\
\text { group } \\
\end{array}$ & $\begin{array}{l}\mathrm{n}(\%) \text { of codable } \\
\text { responses from } \\
\text { tMHFA group } \\
\end{array}$ \\
\hline $\begin{array}{l}\text { Someone else provided } \\
\text { first aid (29) }\end{array}$ & $\begin{array}{l}\text { "The first aid team was } \\
\text { already there" (P517, } \\
\text { baseline) }\end{array}$ & 18.4 & 26.6 & $17(58.6)$ & $12(41.6)$ \\
\hline $\begin{array}{l}\text { Lacked adequate skills or } \\
\text { experience }(22)\end{array}$ & $\begin{array}{l}\text { "Because I am not } \\
\text { confident enough to do } \\
\text { first aid" (P424, baseline) }\end{array}$ & 13.9 & 20.2 & $8(36.4)$ & $14(63.6)$ \\
\hline Practical constraints (16) & $\begin{array}{l}\text { "Could not reach the } \\
\text { person" (P1315, baseline) }\end{array}$ & 10.1 & 14.7 & $7(43.7)$ & $9(56.3)$ \\
\hline $\begin{array}{l}\text { Peer did not need first aid } \\
\text { (11) }\end{array}$ & $\begin{array}{l}\text { "All they needed was a } \\
\text { band-aid" (P1057, } \\
\text { baseline) }\end{array}$ & 7.0 & 10.1 & $6(54.5)$ & $5(45.5)$ \\
\hline $\begin{array}{l}\text { Negative perspective of } \\
\text { first aid or person needing } \\
\text { first aid (10) }\end{array}$ & $\begin{array}{l}\text { "Too weirded out" (P184, } \\
\text { baseline) }\end{array}$ & 6.3 & 9.2 & $5(50.0)$ & $5(50.0)$ \\
\hline No reason $(8)$ & $\begin{array}{l}\text { "There wasn't a reason" } \\
\text { (P822, baseline) }\end{array}$ & 5.1 & 7.3 & $5(62.5)$ & $3(37.5)$ \\
\hline $\begin{array}{l}\text { Student is not sure why } \\
\text { they didn't provide first } \\
\text { aid (9) }\end{array}$ & $\begin{array}{l}\text { "Not sure" (P1591, } \\
\text { baseline) }\end{array}$ & 5.7 & 8.3 & $4(44.4)$ & $5(55.6)$ \\
\hline
\end{tabular}

Note. 115 responses were recorded at baseline and 43 at follow-up. Only categories with responses provided by more than 5 participants are included in this table. Other responses, reported by between 1 and 5 participants, included: being unaware that first aid was needed and no established rapport with the person. Logistic regressions that assessed whether reason for not providing PFA at baseline predicted reason for not 5 providing PFA at follow-up (controlling for age, gender, English as first language, school, intervention received and number of first aid sessions 6 attended) revealed no significant predictors. 